\title{
Lectores y textos escolares durante la primera mitad del siglo XX en Colombia
}

Fecha de recepción: 16 de marzo de 2016

Fecha de aprobación: 29 de junio de 2016

\section{Resumen}

Este artículo presenta algunos aspectos de la historia de la lectura en Colombia durante la primera mitad del siglo XX, así como la caracterización de algunas prácticas lectoras que se hicieron evidentes durante el mismo período. Los intelectuales de los gobiernos de la República Liberal actuaron como agentes culturales claves para ejecutar diversas campañas que coadyuvaron en la ampliación del público lector, entre ellas, los programas de alfabetización, la creación de bibliotecas y misiones culturales. Dentro de estas campañas de alfabetización, se hicieron presentes importantes cambios en el diseño y empleo de los materiales para la enseñanza de la lectura que apuntaron a la diferenciación entre lectores rurales y urbanos.

Palabras clave: historia de la lectura en Colombia, enseñanza de la lectura, textos escolares, público lector, bibliotecas.

Citar: Guzmán Méndez, D.P., \& Marín Colorado, P.A. (julio-diciembre de 2016). Lectores y textos escolares durante la primera mitad del siglo XX en Colombia. LaPalabra,(29),185-197.doi:http://dx.doi.org/10.19053/01218530.n29.2016.5709

Diana Paola Guzmán Méndez Doctora en Literatura (Universidad de Antioquia). Profesora titular del Departamento de Humanidades de la Universidad Jorge Tadeo Lozano; forma parte del grupo de investigación "Mente, lenguaje y sociedad (Universidad Jorge Tadeo Lozano). Es miembro también del grupo de investigación Colombia: Tradiciones de la Palabra (Universidad de Antioquia). dianamayeutica@gmail.com

\section{Paula Andrea Marín Colorado} Doctora en Literatura (Universidad de Antioquia). Investigadora y docente de la maestría en Estudios Editoriales del Instituto Caro y Cuervo. Ha sido becaria del Ministerio de Cultura (Programa Nacional de Estímulos, 2015) y de Colciencias (Programa Doctorados Nacionales, 2012). Es miembro del grupo de investigación Colombia: Tradiciones de la Palabra (Universidad de Antioquia).paulanmc@hotmail.com

* Este artículo de reflexión es parte de los resultados del proyecto "Caracterización del lector en Colombia (18721950)", subsidiado por la Universidad Jorge Tadeo Lozano, y del proyecto ganador de la Beca Instituto Caro y Cuervo de Investigación en Historia de la Edición en Colombia. Colecciones y Catálogos (1919-2014), financiado por el Ministerio de Cultura. 


\section{la palabra}

\section{Readers and School Textbooks during the first half of the XXth century in Colombia}

\section{Abstract}

This article presents aspects of the history of reading in Colombia during the first half of the twentieth century, and the characterization of specific reading practices during this period. Intellectuals of the governments of the Liberal Republic acted as essential cultural agents performing various campaigns that contributed to the expansion of the reading public: creating literacy programs, libraries and cultural missions. Within these literacy campaigns, major changes took place in the design and use of materials for the teaching of reading, which pointed at differentiating rural and urban readers.

Keywords: history of reading in Colombia, reading instruction, textbooks, reading public, libraries.

\section{Lecteurs et manuels scolaires pendant la première moitié du XX siècle en Colombie}

\section{Résumé}

Cet article présente certains aspects de l'histoire de la lecture en Colombie pendant la première moitié du XX siècle, et caractérise des méthodes de lecture pendant la même période. Les intellectuels des gouvernements de la République Libérale ont mis en œuvre des programmes qui ont contribué à développer la lecture : des programmes d'alphabétisation, construction de bibliothèques et missions culturelles. Les transformations de la conception et mise en œuvre des manuels d'apprentissage de lecture des programmes d'alphabétisation, avaient comme but de différencier les lecteurs ruraux des lecteurs urbains.

Mots-clés : histoire de la lecture en Colombie, apprentissage de la lecture, manuels scolaires, lecteurs, bibliothèques. 


\section{Introducción}

Las políticas culturales impulsadas y puestas en marcha por los gobiernos liberales, durante el período de la República Liberal (1930-1946), permitieron transformar la noción de cultura $\mathrm{y}$, específicamente, de la lectura. Estas transformaciones fueron fundamentales para la emergencia de un nuevo público lector en Colombia (variado en sus preferencias, a pesar de la influencia de la Iglesia católica y de los conservadores en las prácticas lectoras), para el afianzamiento del mercado editorial para el libro colombiano y su transición hacia un capitalismo editorial. Dentro de este proceso, el círculo de distribución del libro escolar tuvo una importancia capital que superó el fuero político colombiano. Uno de los planes más importantes dentro del continente, entre las décadas de 1930 y 1960 , fue el proceso de alfabetización y de implantación de prácticas que sirvieran para erradicar "el pecado de la ignorancia". Uno de los elementos más importantes de esta labor recayó sobre el libro y los manuales; las nuevas directrices de la República Liberal habían creado una nueva comunidad de posibles lectores que reclamaban una reforma en las conocidas citologías y manuales importados con el método pestalozziano.

Ese nuevo público no era otro que los adultos, quienes entra- ban al mundo de la lectura. Pero ese público idealizado por el Estado no se limita exclusivamente a los campesinos analfabetas; también volcaron su mirada a los jóvenes que se formaban dentro de las Escuelas Normales colombianas. De esta manera, surge una corriente de libros escolares que ya no se orientan exclusivamente al niño, y que cuentan con el apoyo inmediato de la Unión Panamericana.

Leer en Colombia (primera mitad del siglo $\mathrm{XX}$ )

Cuando el liberalismo volvió a asumir el poder político en el país, en 1930, tras el período de la Regeneración y de la Hegemonía Conservadora, dos de sus campañas más importantes fueron la ampliación de la cobertura educativa y la del incremento de las tasas de alfabetización. Lo anterior no quiere decir que en los años precedentes no se hubiese hecho adelantos en estos aspectos, pero, entre 1930 y 1946, el aumento en el presupuesto para el funcionamiento del Ministerio de Educación resultó clave en la ejecución de esas campañas, pese a que este aumento no haya sido suficiente para cumplir con todas las metas propuestas. La atención a la cobertura educativa y a las campañas de alfabetización estuvo acompañada por lo que se podría resumir como un proyecto para hacer del libro un objeto cotidiano entre las "masas populares". Dicho proyecto se concentró en la creación de las Bibliotecas Aldeanas y de las Misiones Culturales, desde 1934, y tuvo entre sus resultados más importantes el incremento del autodidactismo y la búsqueda del lector por fuera del espacio oficial de la biblioteca (Silva, 2012).

Luis López de Mesa, quien asumirá la dirección del Ministerio de Educación, bajo la cual se implementarán los proyectos arriba mencionados, había planteado, desde 1927, la necesidad de crear las Bibliotecas Aldeanas:

Vamos a difundir el libro por toda la república, fundando las bibliotecas aldeanas, de servicio oficial gratuito.

[...] Debe constar [...] de [...] cuatro grupos: una selección de literatura universal [...]; una selección de obras nacionales; una selección de manuales de instrucción [...]; y por último, aquellos libros de consulta.

[...] Es preciso emprender la publicación de estas obras en casa.

[...] Iniciar ediciones de nítida impresión, tipo grande y encuadernación en pasta española, que tengan mayor duración y no 
estropeen la vista de los lectores.

Si no queremos que el campesino continúe siendo analfabeto [...]; si no queremos que continúe el éxodo hacia las urbes tentadoras $[\ldots]$, redimamos a la aldea de su [...] asfixiante vacío espiritual (López de Mesa, 1927).

Este artículo de López de Mesa, junto con dos artículos más de Gustavo Uribe Arango ("La lectura sin cartilla") y Alfonso Araújo ("Cómo se hace una biblioteca"), publicados en 1928, también en la revista Universidad, dan cuenta del creciente interés de estos temas entre algunos intelectuales colombianos que veían la necesidad de transformar las prácticas lectoras y los modos de accesibilidad a la cultura letrada. El de Uribe señala la necesidad de un cambio en los procesos de enseñanza de la lectura (cambiar la memoria auditiva por la memoria visual, según el método de Decroly) (Uribe Arango, 1928); el de Araújo propone la biblioteca como un "complemento de la escuela" y plantea la necesidad de transformar la percepción y función tradicional de este espacio: "Se consideraba a la biblioteca como un organismo muerto, donde llegaban libros [...] que se cuidaban con esmero, como objetos de museo" (Araújo, 1928, p. 607). Araújo, además, dirá que se debía bus- car la manera de habituar a los niños al uso de los libros y de la biblioteca, a través de conferencias, películas y bibliotecas viajeras.

Los tres artículos mencionados se centran en tres aspectos indispensables para comprender la manera en la que se presentan las "revoluciones" de la lectura: 1) La edición de impresos y su puesta en circulación; 2) Los modos de enseñanza de la lectura; 3) El uso de las bibliotecas y los medios de accesibilidad a los impresos. De esta forma, se entiende que las campañas que se adelantaron durante la República Liberal, en relación con estos tres aspectos, conectaban con necesidades que ya habían sido diagnosticadas, pero a las que no se les había dado una solución concreta. Detrás de las preocupaciones de los tres autores de los artículos citados arriba, se percibe, además, un temor a las veloces y profundas transformaciones sociales, económicas y culturales que se estaban produciendo por la creciente migración del campo a la ciudad, y una reacción aprobatoria hacia las nuevas exigencias de modernización y de progreso para todos los estamentos de la población. Aun así, la campaña de difusión del libro por todas las regiones del país, acompañada de una inversión considerable en la edición y publicación de libros nacionales, tanto como la innovación en los métodos de enseñanza de la lectura y la apertura de la biblioteca hacia nuevos públicos-usuarios y nuevos catálogos, hicieron parte fundamental de las transformaciones culturales que se dieron en esta época.

Entre los resultados de estos proyectos, se pueden mencionar: la creación de 1250 Bibliotecas Aldeanas (en departamentos, intendencias y comisarías) para 1939 (Silva, 2012, p. 73); el aumento en un $88 \%$ del promedio en obras consultadas en las bibliotecas, a tan solo un año de haber iniciado con las campañas; 288.328 lectores por año (en las bibliotecas), para 1938 (Samper Ortega, 1940, p. 10); las constantes peticiones de nuevas colecciones y la cantidad de libros desaparecidos de las bibliotecas, pertenecientes todos a la colección de las Bibliotecas Aldeanas (Silva, 2000); y la confianza de los lectores en los libros de los escritores nacionales, gracias a las Ferias del Libro, realizadas desde 1936, en las que fueron determinantes los éxitos de las ediciones baratas de escritores "populares" como José María Vargas Vila y Arturo Suárez (Silva, 2012). Había, pues, un público lector nuevo en Colombia (los jóvenes, los estudiantes, los obreros, los campesinos) que buscaba y confiaba cada vez más en las ediciones colombianas y en los libros de autores colombianos (que empezaban a ganar su lugar luego del anterior predomino de los libros 
importados), y habituado y deseoso de tener esos libros que, antes, no podía comprar porque pensaba que estaban destinados solo a los círculos letrados o porque su precio sobrepasaba el equivalente a su jornal (López Uribe, 2011).

Junto con esta ampliación del público lector, también vino la "amenaza" de la lectura extensiva. Los intelectuales de la República Liberal, por un lado, y la Iglesia católica, por otro lado, se mostraron siempre preocupados por las preferencias lectoras de este nuevo público, que se adecuaban más a las necesidades de autoinstruirse y de entretenerse, que de responder a las exigencias del "buen gusto" de los círculos letrados; igualmente, pese a las prohibiciones de la Iglesia católica y de ciertos círculos conservadores sobre algunos temas, títulos y autores, no fue posible mantener un control estricto sobre las lecturas de esos nuevos y antiguos lectores. Publicaciones periódicas como Cine y Libros (Los libros y la moral, 1948) ${ }^{1}$ y $E l$ Alcázar (Feria de inmoralidad, 1941), así como algunas cartas de los lectores dirigidas al Ministerio de Educación Nacional
(Director de Educación Pública, 1933; Centro Liberal Obrero de Mutuo Apoyo, 1936; Samper Ortega, 1937), exhiben los restringidos criterios morales con los que autoridades religiosas y representantes de los conservadores buscaban limitar el acceso a los libros y el uso de las bibliotecas; son muestra, pues, de las antiguas prácticas coloniales $\mathrm{y}$ decimonónicas sobrevivientes en el siglo XX colombiano, que no frenaron -del todo- los avances en materia de extensión cultural. En este sentido, se puede afirmar que fueron estos usos "populares" del libro los que permitieron también una importante ampliación del público lector y una diversificación del mercado editorial en Colombia, durante la primera mitad del siglo XX.

Esos lectores "populares" entendían que la lectura y la educación eran instrumentos que les permitían mejorar sus condiciones de vida; había, pues, una demanda casi inherente de lecturas por parte de ese nuevo público lector, que encontró en las campañas estatales una respuesta a los largos años en los que los dirigentes parecieron gobernar de espaldas a las ver- daderas necesidades del "pueblo", en materia cultural -y, por supuesto, también en las otras-. Por primera vez, un funcionario público les preguntaba acerca de sus requerimientos, por primera vez se sentían incluidos en un proyecto de país. Esto es claro cuando se revisan los formularios del Censo Intelectual llevado a cabo por Daniel Samper Ortega, director de la Biblioteca Nacional, en 1933, y que se dividió en dos partes: la primera, un formulario diligenciado por el alcalde de cada población; la segunda, un formulario diligenciado por los "intelectuales" escritores de cada población (profesores, médicos y abogados). Estos formularios fueron la manera concreta en la que la Biblioteca Nacional recibió la información "real" de los futuros usuarios de las Bibliotecas Aldeanas.

El primer tipo de formulario nos permite acceder a información básica acerca de la infraestructura cultural con la que contaba la población (imprentas, bibliotecas, salones de conferencias, publicaciones periódicas, escritores, escuelas y librerías), y de $\mathrm{su}$ funcionamiento en general (servicios públicos, telégrafo,

Aunque Cine y Libros tuvo el propósito de "clasificar y dar a conocer la opinión de moralidad sobre los autores colombianos vivos, y aún sobre aquellos fallecidos cuyas obras son leídas", esto no se cumplió. Las prohibiciones fueron siempre sobre obras y autores extranjeros, entre los que figuraron Vicente Blasco lbáñez, Paul Bourget (uno de los autores preferidos por el público lector colombiano durante toda la primera mitad del siglo XX), Benito Pérez Galdós, Somerset Maughan (uno de los autores más vendidos en las Ferias del Libro), Alejandro Dumas (padre e hijo), Marcel Proust, André Maurois, Thomas Mann (otro de los más exitosos en la Feria del Libro), Jean-Paul Sartre, Aldous Huxley, Anatole France, Gabriel D’Annunzio (otro de los autores más leídos durante la primera mitad del siglo XX), Honoré de Balzac, Emile Zolá, Stendhal, Descartes, Maurice Maeterlink, León Tolstoi y Wolfgang Goethe. 
clima, día de mercado, enfermedades más frecuentes en los humanos y en los animales, estado de las carreteras) (Biblioteca Nacional de Colombia, 1933b). El segundo formulario nos permite conocer información sobre las actividades de los hombres de letras de las poblaciones (libros publicados, publicaciones periódicas en las que colabora, sociedades a las que pertenece, si posee o no biblioteca y de cuántos volúmenes, preferencias de lecturas) (Biblioteca Nacional de Colombia, 1933a). Los datos recopilados a través de estos formularios nos posibilitan comprender mejor las condiciones en las que nuestros intelectuales (más de 2000 fuera de Bogotá) desarrollaron su silenciosa labor en poblaciones apartadas de la capital del país y el desconocimiento -por no decir abandono- que había de ellas por parte del Estado.

Sin excepción, en todas las poblaciones piden libros de pedagogía, de agricultura, de minería, de historia de Colombia, de derecho, de civismo y, en último lugar, obras literarias; asimismo, piden, en general, un radio, una línea telegráfica (en las muchas poblaciones donde todavía no existía), cine educativo, una imprenta y, en varios casos, instalación de luz eléctrica, de alcantarillado y construcción de carreteras, así como ayuda para combatir enfermedades y el alcoholismo en la población. Sobre estas solicitudes, es preciso resaltar, por un lado, la claridad que existe en la diferenciación entre las lecturas útiles y aquellas en las que confluían la autoinstrucción y la entretención, pero también en que ambas eran necesarias; por otro, la claridad acerca de la falta de una infraestructura "moderna", tanto en el nivel material como en el cultural, entendiendo igualmente ambos como necesarios.

A estas necesidades culturales trataron de responder las $\mathrm{Bi}$ bliotecas Aldeanas y las Misiones Culturales, que visitaron periódicamente las poblaciones llevando películas, conferencias y bibliotecas ambulantes. Los libros desaparecidos de las Bibliotecas Aldeanas (constituidas por colecciones literarias, manuales, cartillas y libros de consulta) demuestran que, si bien había una necesidad de estas lecturas útiles, sobre todo, por parte de los adultos, también había una necesidad de lecturas de entretenimiento "instructivo", por parte, sobre todo, de los jóvenes y de los niños; la coexistencia y el reconocimiento de ambas (practicadas por estos lectores "rurales") actuaron como condiciones a favor de la consolidación del capitalismo editorial colombiano. Por esta razón, resulta anacrónico el discurso de Rafael Maya en 1951, en la inauguración de la Feria del Libro (celebrada tras varios años de interrupción, durante los gobiernos conservadores que vinieron tras el fin de la República Liberal), en donde afirmaba: "El libro no tiene más utilidad que la de ser leído" (Maya, 1951, p. 543). Maya obviaba -o desconocía- las transformaciones que se habían operado en los años anteriores frente al uso del libro y a la práctica de la lectura, y buscaba legitimar, de nuevo, una "cultura aristocrática", basada en el desinterés y en las prácticas de exclusión del "buen gusto".

Por su parte, los formularios diligenciados por escritores o intelectuales permiten observar una variedad de intereses de lectura, entre los que predominan el comunismo y las cuestiones obreras, las religiones orientales, la agricultura, las biografías y memorias, la historia patria y las literaturas francesa, italiana, española y colombiana, además de los libros de pedagogía, medicina y derecho, que siempre figuran en las peticiones, y que respondían a las necesidades profesionales de estos intelectuales: profesores, médicos $\mathrm{y}$ abogados. Muchos de ellos se quejan de su estrecha situación económica, que no les permite comprar libros (para ellos, pero también para la educación de sus hijos) ni publicar sus textos; también del aislamiento en el que deben desarrollar su labor, por falta de estímulo y de comunicación e intercambio con sus otros colegas de otras poblaciones y, sobre todo, de la capital. Para estos intelectuales, las publicaciones periódicas y la radio 
eran los medios privilegiados para sentirse conectados y actualizados con lo que sucedía en el resto del país y en su propia profesión, pese a que mucha de la prensa nacional no llegara hasta sus poblaciones, $\mathrm{y}$ a que el aparato de radio (comunitario) se mantuviera dañado la mayor parte del tiempo. Seguramente, estos comentarios ayudaron a decidir a Daniel Samper Ortega, definitivamente, sobre la pertinencia de llevar a cabo los proyectos de las Bibliotecas Aldeanas y de las Misiones Culturales.

Finalmente, el análisis de los datos de registros sobre la propiedad intelectual entre 1929 y 1947 permite concluir que los temas de los títulos más registrados eran los relacionados con textos escolares (37), a los que seguían las obras literarias (34), los manuales y guías (31), y las piezas musicales (14) (Archivo General de la Nación, s.f.; Solicitudes e inscripciones en el Registro de la Propiedad Literaria y Artística, 1946-1947). ${ }^{2}$ La sumatoria de los textos escolares y de los manuales y guías superan con creces el número de obras literarias registradas, hecho que señala el predominio de los libros educativos (en los niveles básico y técnico) en ese proceso de profesionalización y en el de afianzamiento del capitalismo editorial colombiano, así como la demanda constante de un público lector por textos con los que podían solucionar problemas concretos y responder a sus expectativas de autoinstrucción y de progreso.

Ni un colombiano que no quiera aprender, ni un colombiano que no quiera enseñar: la circulación del libro escolar en las escuelas normales

En 1948, se llevó a cabo en Caracas el "Seminario Regional de Educación en la América Latina", cuyo tema central fue la alfabetización como responsabilidad estatal. Uno de los resultados que arrojó este encuentro, patrocinado por la Unión Panamericana y del cual da cuenta Agustín Nieto Caballero, es que la escuela para la infancia no erradicaría un mal que llevaba asentado por años en la población colombiana; era necesario que los adultos, en su mayoría campesinos, tuvieran acceso a la educación. Recordemos que, como lo ha mencionado Doris Lilia Torres, la educación, al iniciar el siglo XX, fue la gran perjudicada, si pensamos en una centuria que abre con una guerra, en las escuelas que eran empleadas como cuarteles, en un país en donde no circulaban los textos escolares, podemos imaginarnos que los progresos en esta materia fueron lentos (Torres, 2010, p. 274).
Dicha relación es, a nuestro parecer, el puente más claro entre el Estado y el país rural; a través del vínculo entre la educación para adultos auspiciada por el Estado y las Normales, se puede develar la mirada y la representación que el gobierno había construido de los campesinos. La pregunta por cómo leían los campesinos y cómo se preparaban los normalistas para enseñarles a leer, resulta en una alianza íntima que no puede desarticularse. Si bien reconocemos la importancia de ACPO en esta dinámica, no tocaremos el material educativo de Radio Sutatenza, sino exclusivamente los libros y manuales que compartían los futuros profesores formados en las Escuelas Normales.

El esplendor que experimentó la empresa editorial a partir de la década de los treinta, tuvo en el libro escolar uno de los bastiones más importantes; sin embargo, los libros escolares eran, en su mayoría, importados y distribuidos por librerías específicas y autorizadas por el Ministerio de Educación. Colecciones como la Araluce o la Biblioteca Losada, compartían los estantes de las bibliotecas con la Biblioteca Aldeana o la colección Samper Ortega. Al parecer, cada una de las colecciones cumplía con un cometido específico que, a su vez, se

2 Bogotá y Medellín son las ciudades que concentran la mayoría de estos registros; a estas les siguen -con un número mucho menor- Cali, Cartagena, Popayán, Bucaramanga, Manizales y Barranquilla. 
relacionaba con el rol social del lector $\mathrm{y}$, además, evidenciaban la concepción que el Estado tenía de la lectura como parte fundamental del desarrollo nacional. La educación era asunto del gobierno, como lo propuso el Olimpo Radical (1863-1886) y lo preservó la República Liberal.

El gobierno conservador de Mariano Ospina (1946-1950) continuaría con la idea de alfabetizar las regiones rurales, como dinámica propia de la noción de progreso. En este sentido, la lectura se estructura en un modelo desarrollista cuyo objetivo principal es la salida al subdesarrollo. La enseñanza de la lectura, que antes cobijaba a la infancia a través de las citolegías $^{3}$, comienza a evidenciar la necesidad de la alfabetización; enseñar a leer y a escribir a los adultos significaba un reto que las Normales y el gobierno quisieron explorar con mucho interés. Pero resulta vital entender la diferencia que existía entre educar e instruir a un niño y alfabetizar a un adulto; de hecho, en las Escuelas Normales se formaban profesores dedicados a estas misiones educativas que marchaban de pueblo en pueblo y que abrían un espacio alternativo, en su mayoría nocturno, para que los estudiantes mayores aprendieran a leer y a escribir.

Legislar sobre la educación, y en específico sobre los modos como se enseñaba a leer, convierte la escuela, los libros y al futuro lector en campos de batalla, en un modo de disciplinamiento del sujeto. Dicho disciplinamiento resulta en una representación del lector y era el reflejo del lugar social configurado por las instancias de poder $^{4}$. Una de las prácticas más importantes de esta dominación simbólica es la clasificación de los lectores y, por ende, de los materiales de lectura.

Estas diferencias también se evidencian en los materiales de enseñanza. En 1872, la misión pedagógica alemana no solo asume la planeación y dirección de siete Escuelas Normales en diferentes estados de la República, sino que el gobierno na- cional firma en 1873 un acuerdo con la casa editorial Hachette \& Compañía. La compra, que tuvo un valor de 800 pesos, se distribuye entre gabinetes de ciencia, libros de texto, silabarios y hasta pianos. Los elementos enviados a escuelas de los estados de Boyacá y Cauca se centran en libros sobre agricultura, cuidado de los animales y literatura. En el caso de las escuelas situadas en los estados de Cundinamarca y Antioquia, prevalecen los libros que enseñan el francés y los pianos para las clases de música.

Esta división entre el lector rural y el urbano, que inicia en el Olimpo Radical, hace evidente que la representación del lector campesino como un sujeto con poco tiempo y habilidades, y que además debe aprender rápido para vincularse a la producción de manera inmediata, es resultado de la concepción que el Estado tenía de la población rural como cuerpo-máquina, cuyas necesidades no se concentran en la educación sino en la instrucción. La división entre los lectores del campo y los de

3 Las citolegías son una serie de publicaciones propias de finales del siglo XIX y principios del XX a través de las cuales se enseñaba a leer y escribir a través de la relación entre imágenes y palabras. Algunas se basaban en el método silábico, otras, en el objetivo. Una constante de estas publicaciones en la vinculación de lecciones de moral, higiene y religión.

4 Cuando hacemos referencia al disciplinamiento del sujeto, acudimos a la propuesta foucaultiana, según la cual este sistema de dominación es parte esencial de la relación entre individuo e institución. La primera práctica de disciplinamiento se concentra en los modos de representación que convierten al representado en un cuerpo dócil, instruido y con emplazamientos funcionales que definen su tiempo, su espacio y sus prácticas. Una de las características que comparten los textos empleados en la campaña contra el analfabetismo es la regulación de los tiempos de clase, de trabajo y de ociosidad; además, los libros publicados por la Imprenta Departamental de Cundinamarca, por ejemplo, tienen como principio enseñarles a los estudiantes cómo mantenerse sanos, cuánto tiempo dedicarle a la lectura, cómo emplear su tiempo libre y, sobretodo, cómo mejorar su experticia en el oficio de la agricultura. La editorial Bedout, por su parte, se concentra en la alfabetización para sujetos en tránsito de convertirse en obreros, y los instruye en las letras a través de manuales que les enseñan e ilustran la vida y el comportamiento en las fábricas (Foucault, 1976). 
la ciudad, que sobrevive a lo largo del tiempo y que define la campaña contra el analfabetismo de 1948, también ha de caracterizar y constituir el modo como los libros de texto han de proponerse.

\section{Las bibliotecas de las Norma-} les: batallas y permanencias

Las bibliotecas de las Normales parecen ser muestras de la batalla ideológica que se presentó entre aquellos que se aferraban al método mecánico y otros que se situaban en la propuesta de Decroly cifrada sobre la experiencia y el análisis. La contradicción que evidenció Nieto Caballero en su estudio para su participación en la Comisión Internacional de Educación que se realizaría en Ginebra en 1932, fue la dicotomía entre la práctica del maestro y la teoría que leía en la cátedra de pensamiento pedagógico (Nieto Caballero, 1935). Como lo ha mencionado Torres (2009), ya desde los inicios del siglo XX, durante la presidencia de Rafael Reyes, fue solicitado que dentro de los presupuestos departamentos para surtir de manera conveniente las necesidades y los sueldos de los maestros. Siguiendo a Torres, esto quiere decir que los maestros comenzaron a aparecer en el panora- ma estatal mucho antes de que Don Agustín Nieto Caballero pensara en ellos (Torres, 2009, p. 220).

Estos mismos maestros deberían fundamentar una concepción de la lectura que formará parte de los oficios cotidianos de los campesinos; por esta razón, algunas instituciones, como la Escuela Central de Artes y Oficios fundada por los lasallistas o las escuelas domésticas dirigidas por las Normales femeninas, reproducían el modelo de Decroly sobre una lectura del mundo. En este sentido, la reforma de 1932 con el Decreto 1487 promulga una educación enfocada al progreso material; de allí se deriva que la lectura será un oficio importante dentro de la mano de obra del país.

El camino se iba orientando hacia lo que la Unesco propondría después y a las agendas políticas contra el analfabetismo. Cuando la campaña de 1948 inicia, la unión entre los oficios, la agricultura y la lectura era una realidad que crecía a medida que las nuevas tendencias se instalaban con mayor aceptación. Así, por ejemplo, la Imprenta Departamental de Cundinamarca publica una serie de cartillas y libros de texto enfocados a los estudiantes de las llamadas escuelas de artes y oficios, de las industriales y las rurales.

De nuevo, las Escuelas Normales serán las llamadas a regentar los espacios de enseñanza que el gobierno decretó en la Ley 56 de 1947 (Molano, 1982). Recordemos que el gobierno de Mariano Ospina Pérez estaba abonando terreno para que las industrias extranjeras (especialmente las inglesas) y la industria manufacturera y agrícola crecieran exponencialmente (con un monopolio económico que continúa hasta hoy) ${ }^{5}$.

Las Normales asumen la tarea de dirigir estas pequeñas escuelas, que compañías como Fabricato, Bavaria, Ferrocarriles Nacionales, entre otras, comenzaron a subsidiar. La Imprenta Departamental de Cundinamarca inició la tarea de publicar una serie de libros a los que llamó la Biblioteca del Profesor y que, a diferencia de la colección de Losada, se enfocaba en una educación rural y relacionada con los adultos. Esta colección se vinculó con la Resolución 35 de 1948, en donde se propusieron las bibliotecas populares y circulantes (Estrada Monsalve, 1948).

Un elemento central en las

$5 \quad$ La Ley 56 de 1927 (la llamada ley Uribe) prohibió a los niños menores de 14 años trabajar, solo si presentaban un certificado de estudios. En este sentido, el apoyo a la campaña contra el analfabetismo obliga a las fábricas a crear escuelas de alfabetización para sus trabajadores y sus hijos; esto no solo cumple con los requerimientos para la inversión extranjera, sino que posibilita que la mano de obra más barata (los jovencitos) pueda trabajar legalmente. 
propuestas que caracterizan la campaña contra el analfabetismo, es la aparición permanente de la categoría "popular" 6 . La relación que se evidencia en el propio decreto que regula la campaña, es de una mediación letrada y una individualización de los lectores. Es así como se diferencian niños de niñas, campesinos de citadinos, campesinos de obreros; es evidente que dicha especificación conlleva, como lo expresamos anteriormente, un disciplinamiento más eficaz y un control más riguroso.

Las bibliotecas de las Escuelas Normales se convierten en escenarios de circularidad cultural (Ginzburg, 2001); es decir, un intercambio (regulado por la distancia del mediador letrado) entre lo popular y lo oficial. Los profesores normalistas deben tomar clases de agricultura e higiene industrial para poder alfabetizar a los obreros y campesinos; los campesinos deberán "enriquecer" sus valores para entender el alma nacional ${ }^{7}$. Pero aquellas bibliotecas que parecen reguladas por el Estado, también se configuran como espacios de resistencia, cuyo objetivo principal parece ser el de defender el espacio del campesino y su permanencia en el campo $^{8}$.

De hecho, es la Normal de Pasca una de las escuelas a donde llegan las bibliotecas circulantes ${ }^{9}$. Dichas bibliotecas complementaban las llamadas misiones pedagógicas, fundamentadas sobre la campaña contra el analfabetismo y las escuelas subsidiadas por la industria; en este sentido, las bibliotecas de las Normales son instituciones atravesadas por proyectos políticos e ideológicos, superan su función de resguardar y poner a circular los libros y forman parte de la dinámica gubernamental (Lyons, 1998).

Las bibliotecas, como es el caso de la Normal de Pasca y del Instituto Central Femenino de Medellín, se convirtieron en centros de reunión para estas escuelas nocturnas; de hecho, los estantes están poblados de libros de Losada (Biblioteca del Maestro), la colección Araluce, los libros de Bedout y los publicados por la Imprenta del Departamento. Cada uno de estos compartimentos tenía un público objetivo $\mathrm{y}$, a su vez, una intención política que reafirma la idea de la biblioteca como espacio de debate social.

\section{De colecciones y de lectores}

Es evidente que las colecciones

$6 \quad$ Retomando a Gramsci (2002), la noción de cultura popular surge de la necesidad de diferenciar las expresiones no oficiales y populares de las oficiales y de alta cultura. Esa diferenciación de la cultura popular tiene como objetivo visibilizar los sectores obreros y campesinos como parte del progreso y de las posibilidades de inversión.

7 La información del presente trabajo se registró en las bibliotecas de las siguientes escuelas normales: Instituto Superior Femenino (Medellín), Escuela Superior de Instructores (Manizales), Escuela Normal Superior de Pasca y Escuela Normal Superior de Santiago de Tunja.

8 El caso de la Normal de Pasca (Cundinamarca) es, sin lugar a dudas, muestra de esa circularidad cultural. Por ejemplo, la escuela nocturna era subsidiada por Licores de Cundinamarca y se vinculaba a los procesos de alfabetización con los libros de colección Losada y la colección Araluce. Lo que resulta interesante es la aparición de periódicos obreros como El obrero moderno o cartillas de pensamiento cooperativo que formaban parte de la Biblioteca del Profesor y eran editadas por la Imprenta Departamental. Este corpus le propone al campesino opciones para no salir del campo hacia las industrias nacionales; por el contrario, las lecturas lo direccionaban a constituir sus propias cooperativas y negocios en beneficio propio y de su comunidad. Es evidente que la resistencia de los estudiantes y profesores a las políticas de progreso del gobierno ocurren en el mismo escenario subsidiado y protegido por el Estado.

$9 \quad$ Las bibliotecas circulantes fueron importadas de la España republicana e impulsadas por el llamado Instituto Escola. Las bibliotecas circulantes se instituyeron a través de la Resolución 35 de 1948; la idea era que las juntas de alfabetización generaran las recomendaciones del corpus y estas bibliotecas se situaran en los municipios, trasladándose eventualmente a poblaciones más retiradas. Las bibliotecas permanecian un tiempo en algunas veredas y luego regresaban a los municipios; en algunos casos, a las normales. La influencia de la educación republicana tocó irremediablemente a la Normal de Pasca, pues gran parte de los volúmenes de literatura forman parte de los libros editados por el Instituto Escola en su llamada biblioteca literaria del estudiante. Esta colección también se complementaba con la colección española Araluce, que entra a Colombia en 1935 con el apoyo del ministro de Educación Darío Echandía. Vale la pena resaltar también la labor de Daniel Samper Ortega en la distribución de esta colección; de hecho, la Araluce viajaba por Colombia junto con las bibliotecas aldeanas y con la selección Samper Ortega. 
editoriales tenían una intención definida relacionada con la formación social del lector. La colección Losada, dedicada a los maestros, se caracteriza por su vinculación a un sistema laico, liberal e intelectual que procuraba la formación académica del oficio del maestro y que acompañó, como lo hemos dicho antes, las cátedras de pensamiento pedagógico. Los libros de la editorial Araluce identifican una lectura estética, cuya función fundamental es formular un lector que posea un conocimiento universal de la literatura; es curioso encontrar que, en las Normales de territorios rurales, la colección Araluce no es tan numerosa como en territorios más citadinos. La Biblioteca Literaria del Estudiante, editada por el Instituto Escola, no es tan numerosa debido al inicio de la Guerra Civil; sin embargo, tiene una clara tendencia a los títulos clásicos del Siglo de Oro español con prólogos que resaltan los valores republicanos; al igual que la colección Araluce, su presencia es más visible en Normales de ciudades principales (Medellín, Manizales y Tunja).

Otro es el caso de la editorial Bedout y la colección que vincula oficios y aprendizaje básico; el número de libros encontrados en la Normal de Tunja y en la de Pasca, supera visiblemente su presencia en las Normales de Medellín y Manizales (lo cual resulta curioso teniendo en cuenta que la casa Bedout tenía su sede en la capital an- tioqueña). El propósito de estos libros es, claramente, la capacitación del campesino en vías de convertirse en obrero; con una proporción similar aparece el corpus de la Biblioteca del Profesor (Imprenta del Departamento). La diferencia radica en que la casa editorial Bedout está ligada a los planes estatales, mientras que la Biblioteca del Profesor le propone al campesino la posibilidad de permanecer en su territorio. De este modo, la convivencia de ambas colecciones en el territorio de la biblioteca configura un escenario de tensiones y enfrentamientos que definen no solo el canon de lecturas, sino al sujeto lector como agente central de los planes estatales y de las dinámicas sociales.

\section{Conclusiones}

La historia de la edición no puede desligarse de la historia de la lectura, y esto es evidente en lo que se ha presentado en los párrafos anteriores. El incremento de los índices de alfabetización (aunque el analfabetismo siempre haya estado por encima del $40 \%$ ) (Silva, 2012) y de la práctica de la lectura, entre un público que no había sido tenido en cuenta antes para el tipo de campañas culturales adelantadas por los gobiernos de la República Liberal, fueron procesos claves para convertir el libro en un objeto de uso y consumo más cotidiano, en la primera mitad del siglo XX colombiano. Las Bibliotecas Aldeanas y las Ferias del Libro fueron acciones fundamentales para acercar el libro a un nuevo público lector que podía visitar en las noches la biblioteca de su población, luego del trabajo, o podía llevarse el libro a su casa; o bien, que podía visitar la Feria del Libro y encontrar impresos acordes con sus capacidades adquisitivas siempre tan precarias-. Por otro lado, la empatía tradicional del público lector colombiano con la autoinstrucción y la educación influyó en la caracterización de las preferencias lectoras de los colombianos en la primera mitad del siglo XX. Así, el libro escolar y técnico predominó por su gran demanda, tanto dentro del sector oficial como del privado.

El sistema de relaciones que propone Lyons, y que vincula la circulación del libro, hace evidente que fenómenos como el capitalismo editorial no solo puede relacionarse con procesos tan complejos como la profesionalización del editor y del escritor, sino también con la enseñanza de las primeras letras y con la formulación de una tipología de lectores. Los espacios de lectura (Petit, 2001), que se configuran como espacios multiformes y derivados de vínculos variados como la relación entre lectura y política, entre representación y progreso, son muestra de que los lectores son configurados por sistemas editoriales o políticos determinados; sin embargo, estos espacios también son muestra de prácticas de resistencia y agenciamiento que pueden generar no solo nuevos sujetos, sino nuevos lectores y nuevas bibliotecas. 


\section{Referencias}

Araújo, A. (1928). Cómo se hace una biblioteca. Universidad, (108), 607-610.

Archivo General de la Nación (AGN) (s.f.). Solicitudes de inscripción en el Registro de la Propiedad Literaria y Artística. Bogotá, Colombia: AGN, Sección Archivo Anexo, Grupo II, Fondo Ministerio de Educación Nacional, Serie Derechos de Autor, Caja 1, Carpetas 1-4.

Biblioteca Nacional de Colombia (BNC) (1933a). Formularios individuales de escritores. Bogotá, Colombia: BNC, Fondo Aldeano (FA), Serie Instrumentos de Control, Caja 27, Carpetas 205-209.

Biblioteca Nacional de Colombia (BNC) (1933b). Formularios municipales. Bogotá, Colombia: BNC, Fondo Aldeano (FA), Serie Instrumentos de Control, Caja 28, Carpetas 216-221.

Centro Liberal Obrero de Mutuo Apoyo (1936, oct. 24). Carta al ministro de Educación. El Retén, Magdalena. Bogotá, Colombia: Archivo General de la Nación (AGN), Sección Archivo Anexo, Grupo II, Fondo Ministerio de Educación Nacional, Serie Bibliotecas, Caja 1, Carpeta 1.

Director de Educación Pública (1933, sept. 22). Carta al Inspector Nacional de Educación. Santa Marta. Bogotá, Colombia: Archivo General de la Nación (AGN), Sección Archivo Anexo, Grupo II, Fondo Ministerio de Educación Nacional, Serie Bibliotecas, Caja 1, Carpeta 1.

Estrada Monsalve, J. (1948). Campaña contra el analfabetismo. Bogotá: Imprenta Nacional de Colombia.

Feria de inmoralidad (1941). El Alcázar, (102), 1.

Foucault, M. (1976). Vigilar y castigar: nacimiento de la prisión. México: Siglo XXI.

Ginzburg, C. (2001). El queso y los gusanos, el cosmos según un molinero del siglo XVI. Madrid: Península.

Gramsci, A. (2002). La política y el estado moderno: escritos. México: Fontamara.

La biblioteca circulante (1942). Revista de las Indias, (42), 132-133.

López de Mesa, L. (1927). Bibliotecas aldeanas. Universidad, (44).

López Uribe, M. del P. (2011). Salarios, vida cotidiana y condiciones de vida en Bogotá durante la primera mitad del siglo XX. Bogotá: Universidad de los Andes.

Los libros y la moral (1948). Cine y Libros, (300), 3-4.

Lyons, M. (1998). Los nuevos lectores del siglo XIX: mujeres, niños y obreros. En: R. Bonfil et al. 
(dirs.). Historia de la lectura en el mundo occidental (pp. 387-424). Madrid: Taurus.

Maya, R. (1951). El libro, testimonio de cultura. Bolivar, (3), 542-547.

Molano, A. (1982). Evolución de la política educativa en el siglo XX. Primera parte 1900-1958. Bogotá: Universidad Pedagógica Nacional.

Nieto Caballero, A. (1935). Labores de la Dirección Nacional de Educación Colombia. Bogotá: Ministerio de Educación Nacional.

Samper Ortega, D. (1937, ene. 22). Carta al ministro de Educación Nacional. Bogotá. Bogotá, Colombia: Archivo General de la Nación (AGN), Sección Archivo Anexo, Grupo II, Fondo Ministerio de Educación Nacional, Serie Bibliotecas, Caja 1, Carpeta 4.

Samper Ortega, D. (1940). Último informe del director de la Biblioteca. En La Biblioteca Nacional y su Exposición del Libro (pp. 5-52). Bogotá: ABC.

Silva, R. (Comp.) (2000). Historia de las bibliotecas en Colombia: compilación de correspondencia. Bogotá.

Silva, R. (2012). República liberal, intelectuales y cultura popular. Medellín: La Carreta.

Solicitudes e inscripciones en el Registro de la Propiedad Literaria y Artística. (1946-1947). Diario Oficial \# 26024-26608. Bogotá.

Torres Cruz, D.L. (2009). El papel de las escuelas en la construcción de la nacionalidad en Colombia. Una aproximación a la escuela elemental, 1900-1930. Revista Historia de la Educación Latinoamericana, (13), 213-240.

Torres Cruz, D.L., \& Ramírez, T. (2010). El uso de la lectura y la escritura como estrategia para enseñar la higiene en la escuela colombiana de los albores del siglo XX. Revista Historia de la educación Latinoamericana, (15), 271-298.

Uribe Arango, G. (1928). La lectura sin cartilla. Universidad, (94), 167-168. 